\title{
ANÁLISE DE EFICIÊNCIA DA JUSTIÇA DO TRABALHO NO BRASIL
}

\section{Ana Elizabeth Neirão Reymão* Karla Azevedo Cebolão ${ }^{\dagger}$}

\section{RESUMO}

O artigo discute a eficiência dos Tribunais Regionais do Trabalho no Brasil, usando a Análise Envoltória de Dados (DEA). Aplicada pelo CNJ, a DEA vem sendo utilizada para analisar, comparar a eficiência, definir as metas dos magistrados e outros aperfeiçoamentos no funcionamento dos tribunais judiciais. A pesquisa é aplicada, de abordagem quantitativa e tem como principais fontes de informação o Justiça em Números e o banco de dados do Sistema de Estatísticas do Poder Judiciário. O estudo mostrou resultados muito positivos sobre os TRTs, mas esclarece que os resultados precisam ser interpretados dentro dos limites do método.

Palavras-chave: Eficiência. Judiciário. Justiça do Trabalho. Conselho Nacional de Justiça. DEA.

\section{EFFICIENCY ANALYSIS OF LABOR JUSTICE IN BRAZIL}

\begin{abstract}
The paper discusses the efficiency of the Regional Labor Courts in Brazil, using Data Envelopment Analysis (DEA). DEA has been used by CNJ to analyze, compare efficiency, set magistrates' goals and other improvements in the functioning of the judicial courts. This research is applied, uses a quantitative approach and the main sources of information are Justice in Numbers Report and the System of Statistics of the Judiciary database. The study shows very positive results on TRTs, but remember that the results must be interpreted in the limits of the method.
\end{abstract}

Keywords: Efficiency. Judiciary. Labor justice. National Council of Justice. DEA.

\section{INTRODUÇÃO}

O objetivo desse artigo é discutir a eficiência dos Tribunais Regionais do Trabalho no Brasil (TRTs), calculada segundo o método da Análise Envoltória de Dados (DEA, do inglês Data Envelopment Analysis), aplicado pelo Conselho Nacional de Justiça (CNJ).

O DEA é um método criado por Charnes, Cooper e Rhodes (1978) e aperfeiçoado em 1984 por Banker, Charnes e Cooper (FOCHEZATTO, 2010). Seu uso nas análises do judiciário pode ajudar a medir sua eficiência, identificar falhas e propor aperfeiçoamentos em

\footnotetext{
* Economista, professora do Programa de Pós-Graduação em Direito do Centro Universitário do Pará (CESUPA) e da Faculdade de Economia da Universidade Federal do Pará (UFPA). E-mail: bethrey@uol.com.br.

${ }^{\dagger}$ Mestre em Direito, Políticas Públicas e Desenvolvimento pelo Centro Universitário do Pará (CESUPA). Email: karlacebolao@yahoo.com.br.
} 
favor do bom cumprimento das funções desse Poder. Em um contexto de escassez de recursos públicos e baixa confiança social no funcionamento das instituições brasileiras, a celeridade, eficiência e efetividade da tutela jurisdicional assumem papel de destaque no debate sobre o judiciário, em favor de seus objetivos de decidir os conflitos e pacificar as questões sociais.

Desde 2012 o método vem sendo utilizado pelo Conselho para comparar a eficiência dos tribunais brasileiros, divulgando seus resultados nos Relatórios Justiça em Números e os utilizando para definir as metas dos magistrados no país.

Ainda são poucos estudos empíricos que visam mensurar o funcionamento da Justiça do Trabalho brasileira, pretendendo esse texto estimular novos estudos nessa área. Dentre os poucos já efetuados, destacam-se os de Nogueira et al. (2012), Fochezatto (2010), Santos Neto et al. (2016), Yeung e Azevedo (2009, 2012) e Yeung e Garcia (2014).

A eficiência é aqui definida como a capacidade de maximizar resultados com o menor uso possível dos recursos. No método DEA, ela é calculada a partir da relação entre os produtos resultantes de um "processo produtivo" e a quantidade de recursos utilizados pela respectiva organização, definindo uma medida numérica como resultado, em que: E $($ eficiência $)=($ produto $/$ recurso produtivo $)$.

A Justiça do Trabalho é uma instituição voltada à pacificação de conflitos nas relações de trabalho. A ela compete assegurar a imprescindível estabilidade das relações sociais, possuindo diversas funções: tutelar, econômica, política, coordenadora e social. Analisar sua eficiência torna-se relevante não apenas pelos fins a que se destina, mas porque há uma tentativa de colocar em pauta sua extinção no país.

Qual a eficiência dos Tribunais Regionais do Trabalho (TRTs), considerando suas 24 regiões? Essa é a pergunta-problema do presente artigo.

Metodologicamente, o texto traz resultados de uma pesquisa aplicada, pois visa gerar conhecimentos para aplicação prática, dirigidos à solução de problemas específicos (GIL, 2007): identificar os tribunais eficientes e ajudar a aperfeiçoar a eficiência dos demais. Por empregar o método DEA, a abordagem é quantitativa. Como procedimentos, usa-se a revisão bibliográfica e a análise documental, tendo como principais fontes de informação os Relatórios Justiça em Números e o banco de dados do Sistema de Estatísticas do Poder Judiciário, de acesso público no sítio oficial do CNJ na internet, conforme regulamenta a Portaria $\mathrm{n}^{\mathrm{o}} 216$, de 19 de dezembro de 2012.

O texto está estruturado em seis seções. Após essa introdução, tem-se uma breve apresentação da Justiça do Trabalho. A seção 3 discute a importância da análise da eficiência 
do Poder Judiciário para a melhoria dos serviços públicos. Na seção 4, apresenta-se a Análise Envoltória de Dados (DEA) e seu uso em estudos sobre os tribunais judiciais, assim como a pesquisa acadêmica e o emprego do método pelo CNJ. Na seção 5, faz-se uma avaliação de eficiência dos TRTs, conforme modelo DEA proposto nesse artigo e sua comparação com o do IPC-Jus, calculado pelo CNJ. Ao final, expõe-se as conclusões do trabalho.

\section{UMA BREVE APRESENTAÇÃO DA JUSTIÇA DO TRABALHO}

A Revolução Industrial, no século XIX, criou historicamente o ambiente para o surgimento do Direito do Trabalho, uma vez que o trabalho humano era cada vez mais explorado e precarizado. $\mathrm{O}$ advento da máquina a vapor foi o marco inicial para a produção em escala, em que o homem passou a ser substituído pela máquina, o que permitiu uma série de desdobramentos, dificultando a barganha entre empregados e empregadores, dada a enorme falta de postos de trabalho (CASSAR, 2017).

A ideologia liberal, adotada à época, defendia a intervenção mínima do Estado na economia e nas relações de trabalho entre empregado e empregador. Nesse ambiente, a contratação das condições de trabalho era livre, o que desencadeou inúmeras consequências negativas para essa relação, como: acidentes de trabalho, doenças endêmicas, exploração de mulheres e crianças em situações insalubres e perigosas, jornadas de trabalhos extensas sem descanso e com salários aviltantes, e outras (ALEXANDRINO; BARRETO; PAULO, 2006).

Todo esse cenário, em que as partes eram livres para contratar, mostrou a necessidade de intervenção do Estado nessas relações, dadas às péssimas condições gerais de trabalho a que eram submetidas as pessoas.

As primeiras leis trabalhistas para proteção do trabalhador surgiram na Inglaterra, berço da Revolução Industrial, em 1802. No Brasil, a política trabalhista iniciou em 1930 com Getúlio Vargas, sendo a Constituição de 1934 a primeira a trazer diversos direitos trabalhistas, como o salário mínimo, jornada de trabalho de 8 horas diárias, férias anuais remuneradas, proteção do trabalho das mulheres e dos menores, etc. (MARTINS, 2017).

O Direito do Trabalho se mostrou necessário para compensar, por meio das desigualdades jurídicas, as grandes desigualdades econômicas existentes entre trabalhadores e empregadores e para criar um ambiente de trabalho mais favorável, em que houvesse a observância de garantias mínimas para os trabalhadores. Tanto que a Constituição Federal de 
1988 (arts. $7^{\circ}$ a 11 ) trata dos direitos trabalhistas enquanto direito social prescrito no art. $6^{\circ}$ do mesmo diploma legal, assim como o faz a Consolidação das Leis do Trabalho (CLT).

O Direito do Trabalho permite a imprescindível estabilidade das relações sociais, possuindo as funções: tutelar, econômica, política, coordenadora e social. Função tutelar, pois procura garantir o mínimo de direitos ao trabalhador, o protegendo de cláusulas abusivas. A função econômica diz respeito à democratização do acesso às riquezas. A função coordenadora ou pacificadora visa harmonizar os conflitos naturais existentes entre capital e trabalho. A função política diz respeito ao interesse público, uma vez que toda a população é atingida pela medida estatal coletiva. A função social, por sua vez, concerne à melhoria da sociedade por meio da melhoria da condição social do trabalhador (CASSAR, 2017).

Nesse contexto, a Justiça do Trabalho é fundamental para a estabilidade das relações sociais, mas alguns argumentos vêm sendo apresentados propondo sua extinção, a exemplo do que ocorreu há dez anos com o sistema de fiscalização da Previdência, tendo seus servidores passado a integrar os quadros da Receita Federal, transformada em super-Receita. A Justiça Federal poderia, propõe-se, absorver os magistrados e servidores da Justiça Trabalhista.

Um dos principais argumentos é o alto custo dessa justiça especializada, o que ganha força no ambiente de cortes orçamentários que vêm ocorrendo no país. Outro argumento é o que questiona a grande valorização das testemunhas como meio de prova, mesmo quando se pode solucionar o litígio por meios mais precisos, como a perícia, por exemplo. Por fim, uma terceira motivação contrária à Justiça Trabalhista é quanto à defesa da hipossuficiência do trabalhador, o que traria uma tendência pela proteção excessiva do mesmo, inviabilizando as empresas e o crescimento econômico, por exemplo.

Ora, as leis trabalhistas são direitos sociais conquistados historicamente em um contexto de lutas e negociações. Em uma democracia, a combinação simultânea entre liberdades civis, políticas e sociais resulta em uma ampla pactuação entre os diversos segmentos de uma sociedade, expressa em sua Constituição. Por essa razão, os princípios Constitucionais precisam ser obedecidos. Várias críticas sobre a atuação da Justiça do Trabalho também poderiam ser feitas à Justiça Federal, Estadual e até às Cortes Superiores, como o Superior Tribunal de Justiça, mas não se fala em sua extinção.

Em comparação com a média do Índice de Produtividade Comparada da Justiça (IPC-Jus), disponibilizada pelo Relatório Justiça em Números 2017, referente ao ano de 2016, tem-se que a média de eficiência é de $82 \%$ para a Justiça Estadual, 90\% para a Justiça do Trabalho e de $63 \%$ para a Justiça Federal. Observa-se que a Justiça do Trabalho é a mais 
eficiente entre as três justiças citadas, o que afasta os argumentos apresentados para a sua extinção.

A análise da eficiência, portanto, é fundamental para acompanhar o desenvolvimento de cada justiça, melhorá-las e corrigir suas falhas, como exposto a seguir.

\section{EM BUSCA DA EFICIÊNCIA}

A pressão sobre organizações públicas e privadas em busca da eficiência é influenciada pela crescente dificuldade de obtenção de recursos, especialmente nos orçamentos públicos. O desenvolvimento de métodos para medi-la assume relevo ao ajudar a identificar falhas e propor aperfeiçoamentos nas organizações.

A reivindicação social para o bom funcionamento da gestão pública vai ao encontro à necessidade de se conhecer a eficiência por meio de um método confiável. O judiciário, enquanto importante poder da República, sofre pressões para que bem cumpra suas funções, ou seja, pacificar as questões sociais e decidir os conflitos. Então, a eficiência da tutela jurisdicional assume papel de destaque.

Otimizar o agir do Estado e a realização dos fins prezados pela sociedade foram e são cada vez mais reclamados, questionando-se a qualidade, omissão e aptidão desse agir em um Estado democrático e social, que deve executar e fomentar a prestação de serviços coletivos essenciais de forma satisfatória e eficiente. Resultados relevantes socialmente devem ser apresentados para justificar os recursos extraídos da sociedade. Percebe-se que essas exigências não são mais somente em termos políticos ou econômicos, mas também jurídicos, encontrando-se positivadas, como exigências do ordenamento nacional (MODESTO, 2000).

Tornou-se, então, essencial aumentar a qualidade dos serviços, em que o beneficiário é o cidadão, uma vez que os agentes públicos devem agir com rapidez, presteza, perfeição e rendimento. Segundo o Princípio da Eficiência, a administração pública não deve desempenhar seu papel apenas com legalidade, mas, fundamentalmente, trazer resultados positivos para o serviço público, em que haja o satisfatório atendimento das necessidades da sociedade (CAMARGO; GUIMARÃES, 2013).

Nesse contexto, editou-se a Emenda Constitucional no 19/1998 que introduziu o princípio da eficiência para melhorar a qualidade dos serviços públicos, assim como a reforma administrativa do Estado brasileiro, incorporando alguns elementos do modelo de administração pública gerencial ao setor público. 
Marco e Medeiros (2016) advogam que o que se pretendia com a positivação do Princípio da Eficiência foi dar um retorno à população que esperava uma administração desburocratizada e rápida, sem esquecer a qualidade, imparcialidade e transparência na entrega de sua atividade fim.

Nesse contexto, surgiu o princípio da administração da justiça, pelo qual o judiciário deve assegurar que a entrega da prestação jurisdicional seja desburocratizada, célere, imparcial, transparente e que vise o bem comum para atender ao princípio da eficiência. Portanto,

Trata-se de um conjunto de deveres-poderes imposto ao Poder Judiciário visando a satisfação das necessidades e interesses públicos, ou seja, para que a entrega da tutela jurisdicional seja efetuada dentro de um tempo célere, (...) (MARCO; MEDEIROS, 2016, p. 365).

A necessidade de uma justiça mais ágil e eficiente conduziu a edição da Emenda Constitucional $\mathrm{n}^{\mathrm{o}}$ 45, em 2004, em que a transparência, moralidade e coordenação administrativa foram o mote, assim como a criação do Conselho Nacional de Justiça (CNJ) órgão responsável pelo controle administrativo e financeiro do Poder Judiciário brasileiro.

Devido à tendência de desenvolvimento de sistemas de mensuração de desempenho, o CNJ, a partir de 2006, passou a recolher e sistematizar dados estatísticos concernentes a aspectos diretamente relacionados ao desempenho das organizações judiciárias brasileiras, como insumos, dotações orçamentárias e dados sobre litigiosidade e acesso à justiça, fazendo a sua divulgação por meio do relatório anual chamado Justiça em Números.

Ao mesmo tempo, surgiu uma técnica de construção de fronteiras de produção com a utilização de indicadores de eficiência produtiva no campo da medição de eficiências produtivas e organizacionais. Chamada Data Envelopment Analysis ou Análise Envoltória de Dados (DEA), ela permite uma análise técnica de unidades produtivas não tradicionais que utilizam múltiplos insumos para a produção de múltiplos bens ou serviços (PEÑA, 2008), que será tema da próxima sessão.

\section{ANÁliSe ENVOLTÓRIA DE DADOS E SUA APLICAÇÃo NA AVALIAÇÃo DA EFICIÊNCIA DOS TRIBUNAIS REGIONAIS DO TRABALHO}

\subsection{O MÉTODO DEA}


O método DEA é uma das poucas ferramentas para a avaliação de eficiência. Inicialmente foi criado para avaliar o desempenho de unidades produtivas nas áreas da engenharia de produção e industrial, mas logo utilizado para análises de hospitais, escolas e outros setores não tradicionais, como os públicos.

$\mathrm{Na}$ avaliação da eficiência do judiciário, destacam-se os trabalhos de Lewin, Morey e Cook (1982) sobre os tribunais penais nos EUA; de Kittelsen e Førsund (1992), acerca dos tribunais distritais na Noruega; e de Pedraja-Chaparro e Salinas-Jiménez (1996) sobre as cortes supremas na Espanha.

No Brasil, o CNJ, impulsionado pela lógica de buscar uma administração pública voltada a resultados e procurando dar efetividade aos Princípios da Eficiência e da Razoável Duração do Processo, desde 2004, publica o Relatório Justiça em Números. Após 2012 tem utilizado a DEA para comparar a eficiência dos tribunais brasileiros, como os de Justiça Estadual, do Trabalho e Federal.

Uma das principais vantagens do método é sua facilidade de utilização, não sendo necessário conhecer muito bem a função de produção do setor, bem como não exige que se conheçam os preços de mercado dos recursos utilizados (inputs) e produtos gerados (outputs) ou, ainda, assumir hipóteses de maximização de resultados e/ou minimização de custos na decisão dos agentes (YEUNG; AZEVEDO, 2012).

O DEA deve ser empregado na comparação de DMUs (Decision Making Units) que "realizam tarefas similares e se diferenciam nas quantidades dos recursos consumidos e das saídas produzidas" (MELLO et. al., 2005, p. 2535). Uma DMU é uma unidade tomadora de decisão, que aqui são os Tribunais Regionais do Trabalho (TRTs).

O objetivo do DEA é identificar as organizações eficientes e não eficientes, comparando o conjunto de inputs e outputs de cada DMU. Dessa forma, a análise envoltória mensura a capacidade de os TRTs transformarem insumos em produtos.

Entende-se por eficiência a relação entre os produtos resultantes de um processo produtivo e a quantidade de recursos utilizados pela respectiva organização, obtendo-se uma medida numérica, dada por:

$$
\mathrm{E}=(\text { Output/Input }), \text { em que E é a eficiência }
$$

As organizações mais eficientes servem de benchmark, ou seja, as DMUs serão com elas comparadas. Assim, o método se baseia em cálculos de fronteira, identificando as DMUs 
mais eficientes e criando uma fronteira de eficiência relativa com elas. As unidades ineficientes são comparadas com as eficientes e a distância até a fronteira mede o grau de ineficiência (YEUNG; AZEVEDO, 2012).

No método, a eficiência é medida de zero a um (0 a 100\%). Se o resultado é um significa dizer que a DMU possui uma eficiência relativa de $100 \%$. Ao ser menor que um, interpreta-se que é ineficiente em X\%. Exemplificando: se o TRT "Y" tem uma eficiência de 0,8 ou $80 \%$, quer dizer que é ineficiente em 0,2 ou $20 \%$ e, para ser eficiente, precisa melhorar $20 \%$.

Destaca-se que, ao se tratar de eficiência relativa, se um TRT tiver $100 \%$ de eficiência isso não significa que ele não pode melhorar, mas apenas que em relação aos demais é o que tem melhor resultado output/input.

A escolha do modelo DEA a ser empregado é muito relevante e tem impactos diretos nos resultados obtidos na análise. Nesse artigo, adota-se o originalmente desenvolvido por Charnes, Cooper e Rhodes (1978), conhecido como "Modelo CCR", no qual se assume retornos constantes de escala, ou seja, ao aumentar os recursos utilizados, os retornos são proporcionais, mas constante no produto gerado.

Nesse sentido, optou-se por seguir a literatura aplicada ao judiciário brasileiro, a exemplo de Fochezatto (2010), Yeung e Azevedo (2009, 2012), Nogueira et al. (2012), Souza (2015) e Zaidan (2011).

Uma alternativa seria a de empregar a hipótese de retornos variáveis de escala, mas poucos são os trabalhos brasileiros que a adotam, como faz Santos Neto et al. (2016), ao estudar a eficiência dos Tribunais Estaduais brasileiros. Porém, predominam os trabalhos que indicam a existência de retornos constantes.

Como explicam Yeung e Garcia (2014), os magistrados e funcionários do judiciário costumam dedicar uma quantidade específica de tempo para cada processo depositado nas cortes, um "tempo médio", que é praticamente invariável com relação à quantidade de novos processos depositados. A alta burocracia e o excessivo detalhamento de procedimentos que precisam ser cumpridos por um processo no tribunal, associada à não obrigatoriedade de os magistrados brasileiros seguirem precedentes, podem explicar essa invariabilidade do tempo. Então, a tendência é de os juízes analisarem caso a caso, o que indica que o pressuposto de retornos constantes de escala é apropriado para a análise do judiciário brasileiro.

Outra característica do modelo aqui usado é a orientação para o output, ou seja, os resultados da DEA dirão se o TRT produz o máximo possível com os insumos disponíveis e 
indicarão o quanto o Tribunal poderia aumentar seus resultados, mantendo-se o nível de inputs inalterados.

Uma alternativa teria sido escolher a orientação para o input, questionando-se se o TRT usa seus recursos de modo eficiente. Porém, explicam Yeung e Azevedo (2012), para decidir qual das orientações escolher, é necessário saber sobre quais fatores (inputs ou outputs) os gestores têm como influir no processo produtivo estudado.

No caso do judiciário, os insumos (inputs) são, em geral, definidos pelo Poder Legislativo, Poder Executivo ou mesmo pela hierarquia superior dos órgãos judiciais. Ou seja, como os tribunais não determinam esses insumos, o modelo aqui empregado analisará se os TRTs produzem ou não o máximo possível com os insumos disponíveis (se atingem $100 \%$ )

\subsection{BASE DE DADOS E ESCOLHA DE VARIÁVEIS}

A análise da eficiência da Justiça do Trabalho aqui realizada usou informações extraídas do banco de dados do Sistema de Estatísticas do Poder Judiciário que, como já referido, são de acesso público no sítio oficial do CNJ na internet.

É a mesma base que fundamenta a elaboração do relatório "Justiça em Números", anualmente publicado pelo Conselho. A criação desse sistema, em agosto de 2005, teve por objetivo concentrar e analisar os dados encaminhados por todos os Tribunais do país e, com base neles, produzir indicadores para diagnosticar a situação do Poder Judiciário e orientar o planejamento estratégico e, assim, promover a celeridade dos processos e a rápida solução dos conflitos judiciais (CNJ, 2008).

O modelo proposto é o apresentado por Yeung e Garcia (2014), usado para a análise da Justiça Eleitoral (2011-2012). Assim, foram definidos os seguintes inputs:
a) Número total de servidores;
b) Número de magistrados de $1^{\circ}$ grau;
c) Número de magistrados de $2^{\circ}$ grau;
d) Número de magistrados do TRT por 100 mil habitantes;
e) Número de força de trabalho do TRT por 100 mil habitantes; e

\footnotetext{
*Alguns trabalhos adotam orientação para o input, como Fochezatto (2010) e Santos Neto et al. (2016).
} 
f) Área útil em relação à área total do TRT.

Os três primeiros inputs dizem respeito ao pessoal disponível na Justiça do Trabalho, considerando-se que quanto mais pessoas para trabalhar, maior a capacidade de solucionar os conflitos e ser eficiente.

Assim como em Yeung e Garcia (2014), incluir a variável número de magistrados e de força de trabalho por 100 mil habitantes tem como objetivo observar a proporção de magistrados disponíveis para as populações regionais, uma vez que existem áreas pouco habitadas no território brasileiro.

Finalmente, selecionou-se a variável "área útil em relação à área total em metros quadrados", pois quanto maior o espaço físico dos tribunais, maior a capacidade de comportarem salas de audiências e para utilização dos servidores, tornando os processos mais rápidos, podendo mais processos serem julgados ao mesmo tempo, o que poderá aumentar a eficiência do TRT.

Quanto aos outputs do modelo, foram escolhidos:

a) Total de processos baixados no $1^{\circ}$ grau;

b) Total de processos baixados no $2^{\circ}$ grau;

c) Diferença entre novos casos e casos pendentes no $1^{\circ} \mathrm{grau}$; e

d) Diferença entre novos casos e casos pendentes no $2^{\circ}$ grau.

Como em Yeung e Garcia (2014), bem como nos relatórios Justiça em Números do CNJ, os outputs incluem a variável processos baixados, considerando-se que esses representam a quantidade bruta de casos que os tribunais conseguem resolver. Quanto maior o número, mais eficiente o TRT.

Processos baixados são os:

remetidos para outros órgãos judiciais competentes, desde que vinculados a tribunais diferentes; remetidos para as instâncias superiores ou inferiores; arquivados definitivamente e processos em que houve decisões que transitaram em julgado e iniciou-se a liquidação, cumprimento ou execução (CNJ, 2017, p. destaques).

Já os casos pendentes são definidos como:

todos os que nunca receberam movimento de baixa, em cada uma das fases analisadas. Podem existir situações em que autos já baixados retornam à tramitação sem figurar como caso novo. São os casos de sentenças anuladas 
na instância superior, de remessas e retornos de autos (CNJ, 2017, p. destaques).

Ou seja, processos baixados são aqueles remetidos para outros órgãos judiciais, às instâncias superiores ou inferiores ou arquivados definitivamente, enquanto que os pendentes nunca tiveram movimento de baixa.

Por fim, o output sobre a diferença entre novos casos e casos pendentes objetiva, em certa medida, ponderar as regiões trabalhistas, evitando que seu tamanho e o número de habitantes influa na quantidade de processos baixados no TRT em análise. Essa diferença foi calculada para o $1^{\circ}$ e o $2^{\circ}$ graus, cada uma considerando:

Diferença casos novos e casos pendentes $=$ casos novos $_{t}-$ casos pendentes $_{t}$

Assim, empregando as variáveis acima listadas, bem como retornos constantes de escala e orientação para o output, o método foi aplicado utilizando-se o software livre R, disponível em https://www.r-project.org/_e seu pacote rDEA para calcular as eficiências.

\section{RESULTADOS E DISCUSSÕES}

Os resultados da avaliação de eficiência dos TRTs, conforme modelo DEA proposto nesse artigo e sua comparação com o do IPC-Jus, calculado pelo CNJ para medir a eficiência dos tribunais judiciários brasileiros, podem ser observados na tabela 1.

Os dados mostram uma elevada eficiência da Justiça do Trabalho, com 8 tribunais na fronteira de eficiência (100\%): TRT 2 (SP), TRT 3 (MG), TRT 8 (PA e AP), TRT 11 (RR e AM), TRT 15 (SP interior), TRT 17 (ES), TRT 18 (GO) e TRT 22 (PI), conforme coluna "eficiência calculada (A)".

Apenas 4 tribunais tiveram índices igual ou menores que 70\%: TRT 10 (DF e TO, 70\%), TRT 14 (AC e RO, 66\%), TRT 16 (MA, 66\%) e TRT 24 (MS, 70\%).

O CNJ também utiliza o método DEA para comparar a eficiência dos Tribunais do mesmo ramo de atuação e elabora o Índice de Produtividade Comparada da Justiça (IPC-Jus), desde 2013. Comparando-se os dados de 2016, observa-se que os resultados apontam uma eficiência maior no modelo do CNJ. 
Ana Elizabeth Neirão Reymão \& Karla Azevedo Cebolão

Tabela 1 - Medidas de eficiência dos tribunais do trabalho brasileiros (2016)

\begin{tabular}{|c|c|c|c|c|c|c|c|}
\hline Sigla & UF & Porte & $\begin{array}{c}\text { Eficiência } \\
\text { calculada } \\
\text { (A) }\end{array}$ & $\begin{array}{c}\text { Eficiência } \\
\text { (com porte) } \\
\text { (B) }\end{array}$ & $\begin{array}{c}\text { Eficiência } \\
\text { IPC-Jus } \\
\text { (C) }\end{array}$ & $(A-B)$ & $(A-C)$ \\
\hline TRT1 & $\mathrm{RJ}$ & Grande & $74 \%$ & $74 \%$ & $81 \%$ & $0 \%$ & $-7 \%$ \\
\hline TRT2 & SP & Grande & $100 \%$ & $100 \%$ & $93 \%$ & $0 \%$ & $7 \%$ \\
\hline TRT3 & MG & Grande & $100 \%$ & $100 \%$ & $100 \%$ & $0 \%$ & $0 \%$ \\
\hline TRT4 & $\mathrm{RS}$ & Grande & $87 \%$ & $87 \%$ & $82 \%$ & $0 \%$ & $5 \%$ \\
\hline TRT5 & $\mathrm{BA}$ & Médio & $73 \%$ & $100 \%$ & $81 \%$ & $-27 \%$ & $-8 \%$ \\
\hline TRT6 & PE & Médio & $89 \%$ & $100 \%$ & $91 \%$ & $-11 \%$ & $-2 \%$ \\
\hline TRT7 & $\mathrm{CE}$ & Médio & $84 \%$ & $100 \%$ & $90 \%$ & $-16 \%$ & $-6 \%$ \\
\hline TRT8 & PA e AP & Médio & $100 \%$ & $100 \%$ & $100 \%$ & $0 \%$ & $0 \%$ \\
\hline TRT9 & PR & Médio & $80 \%$ & $100 \%$ & $86 \%$ & $-20 \%$ & $-6 \%$ \\
\hline TRT10 & DF e TO & Médio & $70 \%$ & $88 \%$ & $80 \%$ & $-18 \%$ & $-10 \%$ \\
\hline TRT11 & $\begin{array}{c}\text { RR e } \\
\text { AM }\end{array}$ & Médio & $100 \%$ & $100 \%$ & $100 \%$ & $0 \%$ & $0 \%$ \\
\hline TRT12 & $\mathrm{SC}$ & Médio & $94 \%$ & $100 \%$ & $94 \%$ & $-6 \%$ & $0 \%$ \\
\hline TRT13 & PB & Médio & $74 \%$ & $95 \%$ & $82 \%$ & $-20 \%$ & $-8 \%$ \\
\hline TRT14 & $\begin{array}{c}\mathrm{AC} \mathrm{e} \\
\mathrm{RO}\end{array}$ & Pequeno & $66 \%$ & $100 \%$ & $92 \%$ & $-34 \%$ & $-26 \%$ \\
\hline TRT15 & $\begin{array}{c}\mathrm{SP} \\
\text { (interior) }\end{array}$ & Grande & $100 \%$ & $100 \%$ & $100 \%$ & $0 \%$ & $0 \%$ \\
\hline TRT16 & MA & Pequeno & $66 \%$ & $100 \%$ & $70 \%$ & $-34 \%$ & $-4 \%$ \\
\hline TRT17 & ES & Pequeno & $100 \%$ & $100 \%$ & $92 \%$ & $0 \%$ & $8 \%$ \\
\hline TRT18 & GO & Médio & $100 \%$ & $100 \%$ & $99 \%$ & $0 \%$ & $1 \%$ \\
\hline TRT19 & $\mathrm{AL}$ & Pequeno & $79 \%$ & $100 \%$ & $83 \%$ & $-21 \%$ & $-4 \%$ \\
\hline TRT20 & $\mathrm{SE}$ & Pequeno & $82 \%$ & $97 \%$ & $79 \%$ & $-15 \%$ & $3 \%$ \\
\hline TRT21 & $\mathrm{RN}$ & Pequeno & $99 \%$ & $100 \%$ & $90 \%$ & $-1 \%$ & $9 \%$ \\
\hline TRT22 & PI & Pequeno & $100 \%$ & $100 \%$ & $96 \%$ & $0 \%$ & $4 \%$ \\
\hline TRT23 & MT & Pequeno & $75 \%$ & $100 \%$ & $83 \%$ & $-25 \%$ & $-8 \%$ \\
\hline \multirow[t]{2}{*}{ TRT24 } & MS & Pequeno & $70 \%$ & $100 \%$ & $74 \%$ & $-30 \%$ & $-4 \%$ \\
\hline & BRASIL & & $86 \%$ & & $90 \%$ & & $-4 \%$ \\
\hline
\end{tabular}

Fonte: Elaboração própria e CNJ (2017)

Segundo o IPC-Jus, quatro TRTs estão na fronteira de eficiência (100\%): TRT 8 (PA e AP), TRT 11 (AM e RR), TRT 15 (SP interior) e TRT 3 (MG); e 9 também têm eficiência elevada (superior a 90\%): TRT 18 (GO, 99\%), TRT 22 (PI, 96\%), TRT 12 (SC, 94\%), TRT 2 (SP, 93\%), TRT 14 (RO e AC, 92\%), TRT 17 (ES, 92\%), TRT 6 (PE, 91\%), TRT 21 (RN, 90\%) e TRT 7 (CE, 90\%), como se observa na coluna C da tabela 1.

Somente três tribunais tiveram eficiência inferior a 80\%: TRT 16 (MA, 70\%), TRT 20 (SE, 79\%) e TRT 24 (MS, 74\%). 
Essas diferenças são observadas porque, como já explicado, a escolha do modelo DEA a ser empregado é muito relevante e tem impactos diretos nos resultados obtidos na análise.

Embora o modelo adotado pelo CNJ (2017) para o cálculo do IPC-Jus também assuma retornos constantes de escala com orientação para o produto, usa outros inputs e outputs:

- Inputs: (a) processos que tramitam (= processos baixados + processos pendentes) + (b) Despesa total - despesa com pessoal inativo - despesa com projetos de construção e obras + (c) Número de magistrados e de servidores efetivos, requisitados e comissionados sem vínculos - cedidos para outros órgãos.

- Outputs: processos baixados.

A análise de eficiência efetuada pelo CNJ também considera a classificação por portes dos tribunais, pois, a partir do Relatório Justiça em Números 2013 (ano-base 2012), o Conselho passou a classificá-los segundo esse critério, com o objetivo de criar grupos de tribunais com características semelhantes. A separação foi feita em três grupos: grande, médio e pequeno porte.

Para essa classificação, os dados considerados foram: despesa total da Justiça, casos novos, processos em tramitação, magistrados, servidores (incluindo estagiários e terceirizados) e dos servidores da área judiciária. A análise de componentes principais ${ }^{\S}$ foi a técnica estatística empregada.

Seguindo esse critério dos portes, foi calculado um índice de eficiência para os TRTs, cujos resultados estão na coluna B da tabela 1. Como se observa, quase todos os tribunais aparecem na fronteira de eficiência (100\%), à exceção de TRT 1 (RJ, 74\%), TRT 10 (DF e TO, 88\%), TRT 13 (PB, 95\%) e TRT 20 (SE, 97\%).

Nota-se, pois, uma expressiva melhora nos valores em comparação à eficiência calculada a partir dos mesmos inputs e outputs do modelo aqui utilizado, proposto por Yueng e Garcia (2014): os valores da coluna (A-B) são, em maioria, negativos. Quem já era eficiente, continuou sendo. Quem não era, melhorou seu índice. Por exemplo, o TRT 16 (MA), avançou de $66 \%$ para $100 \%$; o TRT 24 (MS) melhorou de $70 \%$ para $100 \%$; no TRT 5

\footnotetext{
§ Essa técnica objetiva selecionar dados usados em uma análise, visando sua redução, eliminação de sobreposições e a escolha das formas mais representativas de dados a partir de combinações lineares. Assim, reduz o número de dimensões a serem analisadas conjuntamente.
} 
(BA), o avanço foi de $73 \%$ para 100\%; o TRT 14 (AC e RO) passou de 66\% para 100\%; o TRT 13 (PB) elevou sua eficiência de 74\% para 95\%; o TRT 20 (SE), melhorou de 82\% para $97 \%$; entre outros.

Porém, o presente artigo argumenta que a classificação por portes adotada pelo CNJ em seu modelo não parece apropriada para análise DEA, uma vez que esse método, cujo objetivo é identificar a DMU eficiente, ou seja, aquela com melhor relação insumo-produto, precisa seguir algumas recomendações, não observadas pelo Conselho.

O método avalia, em um primeiro momento, o desempenho do Tribunal na produção de outputs com os inputs que ele dispõe, identificando a fronteira de eficiência (100\%). Em um segundo momento, compara o valor encontrado em cada Tribunal com essa fronteira. Assim, a eficiência é um conceito relativo que compara o que foi produzido, a partir dos recursos disponíveis, com o que poderia ter sido produzido com esses recursos (MELLO et al., 2005).

A literatura argumenta que o tamanho do conjunto de DMUs a ser analisado influencia no número de unidades que serão consideradas eficientes. Quanto menos DMUs, maior a possibilidade de muitas unidades atingirem a fronteira de eficiência, uma vez que menos comparações serão feitas. Quando o número de unidades analisadas aumenta, os resultados mudam, podendo a DMU que foi eficiente deixar de ser com a inclusão das novas unidades (GUERREIRO, 2006).

Quando o CNJ emprega o método DEA com a divisão por portes, surgem 3 fronteiras de eficiência e isso reduz o número de comparações efetuadas, pois são apenas 5 tribunais de grande porte (TRT 1, TRT 2, TRT 3, TRT4 e TRT 15), 10 de médio porte (TRT 5, TRT 6, TRT 7, TRT 8, TRT 9, TRT 10, TRT 11, TRT 12, TRT 13 e TRT18) e 9 de pequeno porte (TRT 14, TRT 16, TRT 17, TRT 19, TRT 20, TRT 21, TRT 22, TRT 23 e TRT 24) a serem comparados entre si, e não mais 24.

O DEA com a divisão por portes também viola um pressuposto quanto ao número de variáveis de entrada e saída escolhidas no modelo. Para aumentar o poder discriminatório da análise, Fitzsimmons e Fitzsimmons (2005), Fochezatto (2010), Gomes et al. (2005), González Araya (2003), Sinuany-Stern et al. (1994), dentre outros, argumentam que é preciso procurar um ponto de equilíbrio na quantidade de variáveis e de DMUs escolhidas.

Para Fitzsimmons e Fitzsimmons (2005), o número mínimo de variáveis (inputs + outputs) a ser utilizado na análise deve ser pelo menos o dobro do número de DMUs. Fochezatto (2010), citado nos Relatórios Justiça em Números do CNJ, como referência da 
aplicação do método DEA na área forense, é ainda mais rigoroso e recomenda que esse número deve ser o triplo. Para Gomes et al. (2005) e González Araya (2003), deve-se ter o dobro, o triplo ou ainda quatro a cinco vezes este número.

$\mathrm{Na}$ análise da eficiência da Justiça Eleitoral brasileira de Yeung e Garcia (2014), os autores defendem a necessidade de o triplo de DMUs em relação à somatória de inputs e outputs:

\begin{abstract}
Finalmente, cabe listar alguns cuidados necessários na aplicação do método. Uma das características da DEA é a sua parcimônia no uso de dados. Em princípio, para cada DMU basta ter um único dado de output e outro de input e será possível o cálculo da fronteira. Com relação ao número de observações, existe uma regra que indica que o mínimo deve ser de $n=3(\mathrm{p}+$ q), onde p e q são o número de inputs e outputs, respectivamente. Como se pode observar, este número pode ser muito pequeno. Por isso, a metodologia da DEA pode ser muito sensível a erros de medida e a falta de acurácia nos dados. Se a qualidade dos dados não for garantida, e a medida não for claramente definida, os resultados de eficiência derivados podem ficar comprometidos (YEUNG; GARCIA, 2014, p. 218).
\end{abstract}

A soma de inputs e outputs no modelo DEA do CNJ é quatro, então, se o pesquisador adotar a regra do dobro, precisa-se de pelo menos 8 TRTs em análise, o que não ocorre nos tribunais de grande porte, que são apenas 5. Caso a regra empregada fosse a do triplo, seriam necessários pelo menos 12 TRTs em cada porte, o que não ocorre, inviabilizando, desta forma, a análise segundo a classificação por portes, a nosso ver.

Pelas razões acima expostas, as análises nesse artigo não utilizaram essa classificação, sendo todos os TRTs comparados entre si, daí as diferenças encontradas entre a eficiência calculada pelo modelo aqui proposto e o IPC-Jus do CNJ, apresentadas na coluna (A-C) da tabela 1 .

Com apenas uma fronteira, as eficiências precisam ser recalculadas, e alguns tribunais que haviam sido bem considerados pelo CNJ pioraram seus desempenhos, como ocorre, principalmente, no caso dos tribunais de médio e pequeno porte: o TRT 14 (AC e RO) apresentou a maior diferença (26\%), saindo de uma eficiência de $92 \%$ para $66 \%$; o TRT 5 (BA) teve uma diferença de $8 \%$ (passou de $81 \%$ para 73\%); no TRT 13 (PB) a diferença também foi de $8 \%$ (caiu de $82 \%$ para $74 \%$ ) e no TRT 24 (MS) houve uma queda de $4 \%$ (de $74 \%$ para $70 \%$ ), por exemplo.

Porém, isso também aconteceu com o TRT 1 (RJ), de grande porte, em que se observou uma diferença de $7 \%$, passando de $81 \%$ para $74 \%$ de eficiência. 
Essa diferença teve sinal positivo em poucos casos (SP, RS, ES, GO, AL, SE, RN E PI), o que provavelmente pode ser explicado pelo output utilizado no modelo desse artigo. Ao considerar a diferença entre processos novos e processos pendentes, faz com que haja uma ponderação (inapropriada?) quanto ao tamanho da região trabalhista e o número de processos em cada TRT. Entretanto, uma discussão mais aprofundada sobre esse assunto foge aos objetivos propostos nesse trabalho.

Portanto, ainda que as análises aqui apresentadas não encerrem a discussão sobre o tema, os dados mostram uma elevada eficiência da Justiça do Trabalho no Brasil que, no modelo usado nesse artigo, foi de 86\%. Apesar de inferior à calculada pelo CNJ (90\%), esses dados evidenciam que a eficiência dos TRTs é relativamente maior que à da Justiça Estadual $(82 \%)$ e da Justiça Federal $\left(\right.$ TRF $1^{\circ}$ grau $\left.=63 \%\right)$, conforme CNJ (2017).

\section{CONSIDERAÇÕES FINAIS}

$\mathrm{O}$ artigo analisou a eficiência dos TRTs no Brasil e, empregando o método DEA, mostrou que seus indicadores apontam para resultados muito positivos, segundo o modelo aqui utilizado.

O texto iniciou lembrando que a Constituição Federal de 1988 (arts. $7^{\circ}$ a 11) trata dos direitos trabalhistas enquanto direito social prescrito no art. $6^{\circ}$ do mesmo diploma legal, assim como o faz a Consolidação das Leis do Trabalho (CLT). O Direito do Trabalho surgiu como uma forma de compensar as grandes desigualdades econômicas existentes entre trabalhadores e empregadores e criar um ambiente de trabalho mais favorável, em que houvesse a observância de garantias mínimas para os envolvidos no processo produtivo.

Apesar de a Justiça do Trabalho ser fundamental para a estabilidade das relações sociais, alguns argumentos vêm sendo apresentados propondo sua extinção, como o seu alto custo, morosidade e que a defesa da hipossuficiência do trabalhador traria uma tendência pela proteção excessiva do mesmo, inviabilizando as empresas e o crescimento econômico, por exemplo.

Muitas dessa críticas também poderiam ser aplicadas a outras instituições judiciais no país, como a Justiça Estadual e a Justiça Federal que, em comparação com a média de eficiência calculada pelo IPC-Jus (CNJ), tem indicadores mais baixos, revelando-se a Justiça do Trabalho a mais eficiente entre as três justiças citadas, o que enfraquece os argumentos apresentados para a sua extinção. 
A análise da eficiência, portanto, é fundamental para acompanhar o desenvolvimento de cada justiça, principalmente devido à grande pressão sofrida pelas organizações públicas e privadas em busca de aperfeiçoamentos, influenciada pela crescente dificuldade de obtenção de recursos, especialmente nos orçamentos públicos.

Com a ampliação dos controles acerca da atuação das instituições públicas, exige-se rapidez, presteza e efetividade do Estado democrático e social na realização da prestação de serviços coletivos essenciais em que o beneficiário é o cidadão, aumentando a qualidade dos serviços.

A edição da Emenda Constitucional n ${ }^{\circ}$ 45/2004 e a criação do CNJ apontaram nesse sentido, com esse passando a desenvolver sistemas de mensuração de desempenho, com base no método DEA.

Empregando um modelo baseado em Yeung e Garcia (2014), as análises nesse artigo evidenciaram elevada eficiência da Justiça do Trabalho, com 8 tribunais na fronteira (100\% de eficiência) e apenas 4 com índices igual ou inferiores a 70\%, mostrando que a escolha do modelo DEA a ser empregado é muito importante e tem impactos diretos nos resultados obtidos nos indicadores calculados.

Comparando-se os resultados com os do IPC-Jus (CNJ), o artigo mostrou que a tendência geral de indicadores positivos sobre a eficiência dos TRTs no país se manteve, mas alguns tribunais que haviam sido bem considerados pelo Conselho pioraram seus desempenhos. Isso foi mais frequente para os de médio e pequeno porte, embora também tenha acontecido com o TRT $1(\mathrm{RJ})$, de grande porte.

Outra conclusão importante do presente estudo é quanto a classificação por portes adotada pelo $\mathrm{CNJ}$ no modelo em que emprega o método DEA, pois essa não parece apropriada, uma vez que o tamanho do conjunto de DMUs a ser analisado influencia no número de unidades que serão consideradas eficientes. Quanto menos DMUs, maior a possibilidade de muitas unidades atingirem a fronteira de eficiência, uma vez que menos comparações serão feitas. Ou seja, ao reduzir o número de comparações para somente entre aqueles tribunais de mesmo porte, a análise do Conselho não acompanha a literatura sobre o método e viola algumas de suas recomendações.

Por fim, cumpre lembrar que o método apresenta resultados sobre a eficiência relativa das DMUs em análise. Assim, quando um TRT tem 100\% de eficiência isso não significa que ele não pode melhorar, mas apenas que em relação aos demais é o que tem melhor resultado output/input. Como poucos tribunais tiveram índices abaixo de $70 \%$, um 
leitor mais desatento poderia concluir que há pouco o que melhorar no seu funcionamento, o mesmo acontecendo sobre o resultado global (86\%) acerca da justiça trabalhista no país.

Nesse sentido, quando as análises destacaram que a Justiça do Trabalho tem maiores eficiências que a Justiça Estadual e Federal, essa conclusão precisa ser relativizada, posto que, a depender do modelo DEA empregado, os resultados obtidos na análise podem se alterar. Outras pesquisas precisam ser efetuadas para propor melhorias na prestação jurisdicional no país, dada a importância do Direito e da Justiça do Trabalho, instituição fundamental para assegurar os avanços civilizatórios que sua existência sinaliza nas relações socioeconômicas.

\section{REFERÊNCIAS}

ALEXANDRINO, Marcelo; BARRETO, Glaucia; PAULO, Vicente. Direito do Trabalho. 9a ed. Rio de Janeiro: Impetus, 2006.

BANKER, Rajiv; CHARNES, Abraham; COOPER, William Wager. Some Models for Estimating Technical and Scale Inneficiencies in Data Envelopment Analysis. Management Science, v. 30, n. 9, p. 1.078-1.092, 1984.

CAMARGO, Francielle; GUIMARÃES, Klicia. O princípio da eficiência na gestão pública. Revista CEPPG-CESUC-Centro de Ensino Superior de Catalão, Ano XVI, n. 28, 2013.

CASSAR. Volia Bomfim. Direito do trabalho: de acordo com a reforma trabalhista. Lei 13.467/2017. $14^{\text {a }}$ ed. São Paulo: Ed Método, 2017.

CHARNES, Abraham; Cooper, WILLIAM, RHODES, Edward Rhodes. Measuring the Efficiency of Decision-Making Units. European Journal of Operational Research, v. 2, n. 6, p 429-444, nov. 1978.

CONSELHO NACIONAL DE JUSTIÇA - CNJ. Banco de dados do Sistema de Estatísticas do Poder Judiciário. Disponível em http://www.cnj.jus.br/programas-eacoes/pj-justica-em-numeros/2013-01-04-19-13-21_Acesso 18 de fev. de 2018.

Justiça em Números. Várias edições (2004, 2005, 2006, 2007, 2008, 2009, 2010, 2011, 2012, 2013, 2014, 2015, 2016, 2017). Disponível em: http://www.cnj.jus.br/ programas-e-acoes/pj-justica-em-numeros. Acesso em 18 de fev. de 2018.

FITZSIMMONS, James; FITZSIMMONS, Mona. Administração de serviços: operações, estratégia e tecnologia da informação. 4. ed. Porto Alegre: Bookman, 2005.

FOCHEZATTO, Adelar. Análise da Eficiência Relativa dos Tribunais de Justiça Estadual Brasileira Utilizando o método DEA. 2010. Disponível em: http://www.aecr.org/ web/congresos/2010/htdocs/pdf/p50.pdf. Acesso em: 03 de jul. de 2017.

GIL, A. C. Como elaborar projetos de pesquisa. 4. ed. São Paulo: Atlas, 2007. 
GOMES, Eliane Gonçalves; MANGABEIRA, João Alfredo de Carvalho; MELLO, João Carlos Correia Baptista Soares de. Análise de envoltória de dados para avaliação de eficiência e caracterização de tipologias em agricultura: um estudo de caso. Revista de Economia e Sociologia Rural, Brasília , v. 43, n. 4, p. 607-631, 2005. Disponível em: http://www.scielo.br/ scielo.php? script=sci_arttext\&pid=S0103-20032005000400001. Acesso em 15 de nov. de 2015.

GONZÁLEZ ARAYA, Marcela. Projeções não radiais em regiões fortemente eficientes da fronteira DEA - algoritmos e aplicações. Rio de Janeiro, 2003. Tese (Doutorado em Engenharia de Produção) - COPPE, Universidade Federal do Rio de Janeiro.

GUERREIRO, Alexandra dos Santos. Análise da Eficiência de Empresas de Comércio Eletrônico usando Técnicas da Análise Envoltória de Dados. Rio de Janeiro, 2006, 90f. Dissertação de mestrado (Programa de Pós-Graduação em Engenharia de Produção do Departamento de Engenharia Industrial da PUC-Rio).

KITTELSEN, Sverre; FØRSUND, Finn. Efficiency analysis of Norwegian district courts. Journal of Productivity Analysis. September, Volume 3, Issue 3, p. 277-306, 1992.

LEWIN, Arie; MOREY, Richard; COOK, Thomas. Evaluating the administrative efficiency of courts. Omega 10, p. 401-411, 1982.

MARCO, Cristian Magnus de; MEDEIROS, Jeison Francisco de. O princípio da eficiência da administração da justiça como justificativa para implantação de uma jurisprudência precedentalista no Brasil: a disciplina judiciária marcada por influência neoliberal. Revista Jurídica, v. 3, n. 40, p. 358-376, 2016.

MARTINS, Sergio Pinto. Manual de Direito do Trabalho. 10ª ed. São Pulo: Saraiva, 2017.

MELLO, João Carlos; MEZA, Lidia Ângulo; GOMES, Eliane; BIONDI NETO, Luiz. Curso de análise de envoltória de dados. Simpósio Brasileiro de Pesquisa Operacional, v. 37, p. 2521-2547, 2005.

MODESTO, Paulo. Notas para um debate sobre o princípio da eficiência. Revista do Serviço Público, v. 51, n. 2, p. 105, 2000.

NOGUEIRA, José Marcelo Maia; OLIVEIRA, Kátia Michelle Matos de; VASCONCELOS, Alan Pereira de. Estudo exploratório da eficiência dos Tribunais de Justiça estaduais brasileiros usando a Análise Envoltória de Dados (DEA). Revista de Administração Pública. v. 46, n. 5, p. 1317-1340, 2012.

PEDRAJA-CHAPARRO, Francisco; SALINAS-JIMENEZ, Javier. An assessment of the efficiency of Spanish Courts using DEA, Applied Economics, Volume 28, Number 11, Routledge, p. 1391-1403, 1996.

PEÑA, Carlos Rosano. Um Modelo de Avaliação da Eficiência da Administração Pública através do Método Análise Envoltória de Dados (DEA). 2008. Disponível em: http://www.scielo.br/pdf/rac/v12n1/a05v12n1. Acesso em: 20 de set. de 2017. 
SANTOS NETO, Magno dos; SOUZA; Leandro André Cardoso de; BORTOLON, Patricia Maria. Análise da Eficiência dos Tribunais Estaduais do Brasil: Aplicação da Técnica de Análise Envoltória de Dados e Regressão Logística. In: Congresso ANPCONT, 10, 2016, Ribeirão Preto. Disponível em: http://congressos.anpcont.org.br/x/anais/files/201605/cpt234.pdf. Acesso em: 03 de jul. de 2017.

SINUANY-STERN, Zilla; MEHREZ, A.; BARBOY, A. Academic departments efficiency via DEA. Computer Ops. Res., v. 21, n. 5, p. 543-556, 1994.

YEUNG, Luciana Luk-Tai; AZEVEDO, Paulo Furquim de. Além dos "achismos" e das evidências anedóticas: medindo a eficiência dos tribunais brasileiros. Economia Aplicada, v. 16, n. 4, p. 643-663, 2012.

; GARCIA, Gabriel Arsuffi. Análise de Eficiência da Justiça Eleitoral no Brasil. Cadernos Adenauer XV, nº 1, Justiça Eleitoral Rio de Janeiro: Fundação Konrad Adenauer, p. 211-228, 2014.

ZAIDAN, Carlos Alberto Lima. Análise do Poder Judiciário brasileiro: quantificando sua eficiência através da Análise Envoltória de Dados - DEA. Recife: O Autor, 2011. 